\title{
Experience of service provision for adolescents with eating disorders
}

Sharon Rother and Julia Buckroyd Centre for Community Research, University of Hertfordshire, Hertfordshire, UK

\begin{abstract}
Eating disorders of all kinds are common and serious in adolescents and young women. Recent government policies have suggested that adolescent mental health strategies should be developed. They have also laid emphasis on early intervention, accessible local provision and have identified eating disorders as a priority. It is acknowledged that services at primary care level for adolescents with eating disorders are sporadic or nonexistent. It was considered that a service user perspective would be beneficial in contributing to assessing the needs of adolescents with eating disorders. The research project was established to identify the service provision used, if any, by adolescent sufferers of eating disorders and what, in their opinion, would have been desirable at that time. The research consisted of a semi-structured interview with a sample of recovered adult participants to establish their experiences of services they had received as adolescents. Additionally the participants were asked what further help they felt would have been beneficial and where that help would have been usefully situated. The main findings suggest that the majority of health professionals are ill informed and not acutely conscious of the needs of eating disordered adolescents. Only counsellors within the voluntary sector agency showed any real understanding and an ability to help constructively. It was concluded that there is a real lack of help at primary care level and that schools should play a wider role in educating adolescents in a positive belief in themselves and in the destructive nature of an eating disorder.
\end{abstract}

Key words: adolescents; early intervention; eating disorders; service provision; users' views

\section{Rationale}

Eating disorders such as anorexia nervosa, bulimia nervosa and binge eating disorder are amongst the most common mental health problems of our time. They affect large numbers of persons and, in particular, target adolescent and young adult women (Hill and Pomeroy, 2001). Although prevalence figures for the full syndrome in that population are thought to be about $1 \%$ for anorexia and 3\% for bulimia, more recent conceptualisation of terms of diagnosis in the context of a continuum of 'disordered eating' reveals a prevalence as high as 13\% (Piran, 1999; Shisslak et al., 1995). In

Address for correspondence: Sharon Rother, Centre for Community Research, University of Hertfordshire, College Lane, Hatfield, Hertfordshire AL10 9AB, UK. Email: s.m.rother@herts.ac.uk

(c) Arnold 2004 extreme cases of an eating disorder the illness can lead to death. Eating disorders account for the highest recorded death rate for a mental health illness (Hsu, 1995). Even when the illness does not lead to death it can create serious physical, emotional and social consequences which destroy the sufferer's ability to study and can lead to social isolation (Goldbloom and Kennedy, 1995; Mitchell, 1995). Eating disorders also have the highest rate of treatment seeking, in-patient hospitalisation and suicide attempts of any common psychiatric disorder (Hsu, 1995). Additionally, there is evidence that eating pathology predicts the onset of obesity, which results in elevated morbidity and mortality (Stice, 2001).

Anorexia nervosa is characterized by selfimposed starvation. Patients with anorexia nervosa refuse to eat, lose at least $15 \%$ of their body weight, have an intense fear of becoming fat, even

$10.1191 / 1463423604 p c 1920 a$ 
though underweight, and have a distorted body image. In addition, in postmenarchal females, amenorrhoea, that is an absence of at least three consecutive menstrual cycles, is also an indication of diagnosis (DSM IV Diagnostic Criteria for Anorexia Nervosa, 1994). Bulimia nervosa is characterized by recurrent episodes of binge eating. Bulimics engage in behaviours such as purging and excessive exercise to prevent weight gain. To meet the criteria for bulimia nervosa, the bingeing and compensatory activities must occur at least twice a week for three months (DSM IV Diagnostic Criteria for Bulimia Nervosa, American Psychiatric Association, 1994). Binge eating disorder is defined as uncontrollable overeating without the compensatory purging or the excessive exercise characteristics of bulimia nervosa and therefore is associated with obesity (Hill and Pomeroy, 2001). The physical consequences of these practices for anorexics are loss of muscle and bone mass, which in serious cases are irreversible and may sometimes be fatal. Physical consequences of bulimia include electrolyte imbalance, erosion of dental enamel and damage to the digestive system. Emotional consequences of these conditions include social withdrawal, which can impair educational and employment opportunities, and poor self-esteem that can affect emotional and social development (Goldbloom and Kennedy, 1995; Mitchell, 1995).

There is compelling evidence to suggest the gravity of eating and weight related disturbances in children and adolescents. Researchers in the field of obesity, eating disorders and body image disturbances have now redirected their efforts from adults to children and adolescents (Thompson and Smolak, 2001). There seems to be a consensus that there are bi-polar peaks to the onset of eating disorders at the ages of 13 to 14 years and again at 17 years. Furthermore it has been suggested that the earlier the illness is recognized and some intervention can be administered, the more favourable is the prognosis for recovery (Hsu, 1995; Piran, 1999; Steinhausen, 1995). Yet it is also accepted, most recently in a Royal College of Psychiatrists Report (2000), that service provision even at tertiary care level is seriously inadequate and that provision for adolescents at primary and community care level is virtually unknown within the National Health Service (NHS) (East and North Hertfordshire Health Authority etal., 2000a; Robinson,
1993). The need for locally available care is corroborated by surveys that have been carried out by the Eating Disorders Association (Consumer Association, 1998; Newton et al., 1993) suggesting an irregularity of service and considerable dissatisfaction with the services that are available.

Recent Department of Health documents have urged the development of adolescent mental health strategies, laid emphasis on accessible local provision, encouraged early intervention and identified eating disorders as a priority (Department of Health, 1996; 1999). Local implementation papers (East and North Hertfordshire Health Authority et al., 2000b; East and North Hertfordshire Health Authority et al., 2000a; East and North Hertfordshire Health Authority et al., 2000b) have echoed these goals and values. Unfortunately, despite this, Hertfordshire has, as yet, no specialized provision for adolescents with eating disorders at any level. An outpatient service, for patients with eating disorders referred for psychiatric care, is available at Watford General Hospital. This unit is for adults, which means from ages 16 or 18 , depending on when full-time education has ended. Younger adolescents with eating disorders have to be dealt with by the Child and Adolescent Mental Health Service, which is severely overstretched.

Serious and deteriorating cases that require inpatient treatment are given extra-contractual referrals. As a consequence of this, the patient is hospitalized out of the area with associated social and family disruption. Recent literature suggests that inpatient treatment is associated with significantly worse outcomes (Gowers et al., 2000). The only treatments on offer within Hertfordshire are through private specialists or within voluntary sector adolescent counselling centres. Concern about this situation is beginning to develop, as there are thought to be large numbers of adolescents who are not being treated (East and North Hertfordshire Health Authority et al., 2000a).

In considering how to respond to this need, a service user perspective would be very helpful. The Department of Health, 1999, identified the involvement of service users as one of 10 guiding principles for decision making in relation to service delivery. For that reason, a group of sufferers who were not so unwell that they had been referred to a psychiatric service were chosen to contribute to service plans. These young adults have had the benefit of a voluntary sector agency offering 
counselling and support services to people suffering from eating disorders. They were able to provide data covering the 10 years since the Eating Disorder Association carried out the last study of this nature (Newton et al., 1993). Respondents to that study identified a perception of a lack of healthcare personnel competent to work with eating disorders and an associated lack of services. They also expressed a desire for more support for themselves and their families from informed professionals.

One of the problems in obtaining user views on how services should be planned is that few individuals know what can be requested in terms of service provision. The intended sample population for this study has, by virtue of their referral, at least some experience of treatment and therefore may be more able to articulate what would have been useful to them at an earlier stage in their illness. Since the vast majority of eating disorders have adolescent or early adult onset (Hill and Pomeroy, 2001) it seems reasonable to assume that at least a proportion of the referrals to the adult service will therefore have the experience to be able to provide a perspective on this issue. An analysis of the perceptions gathered from this pilot study would enable the creation of a survey instrument that will inform a larger survey to be carried out in due course. The eventual hope is that the results of the larger survey will be available for the planning of services in primary care.

\section{Methodology}

The sample group approached was past adult users of a voluntary sector agency. The project aimed to identify the service provision used (if any) by them, as adolescent sufferers from eating disorders, and what, in their opinion, would have been a desirable provision for them at that time. A flyer headed 'Planning an Eating Disorder Service' was displayed at the agency's premises seeking volunteers to assist in the planning of an eating disorder service for adolescents. It targeted people aged between 18 and 28 and asked if they would agree to be interviewed about their own experiences of any help with their eating disorder that they did or did not receive during their adolescence. Also, a copy of the flyer was sent out under the auspices of the agency to 34 previous service users who had been identified as now being between the ages of 18 and 28, i.e., adolescents during the 10-year period following the publication in 1993 of the Eating Disorders Association study (Newton et al., 1993). The respondents were given a telephone number to contact the researcher where a prerecorded message asked them to leave their name and address and advised them that they would be sent an information pack. The information pack contained a description of the project, brief information about the researcher and an invitation to come for an interview with the researcher at the premises of the agency. Also included were a form asking for basic information and a consent form. Six young women, all of whom had received letters rather than seeing the flyer, responded leaving their details and these respondents were sent the information pack. They were told that having read all the information, if they were still interested in assisting in the project, they should return the personal details form and the signed informed consent form. All six did return the relevant forms and participated fully in the project.

The six participants were then contacted by the researcher and invited to attend a semi-structured interview at a mutually agreed time and date at the agency. The interview began by their being asked for some general information about themselves and their circumstances. It went on to ask about the timing of the onset of their eating disorder and how it had manifested itself; when they first felt they had a problem and needed help; what they felt about any help they might have received at that time and on a continuing basis; what they would have liked at that time; and where they would have liked that help to be based. These interviews were tape-recorded and transcribed and the transcriptions were returned to the participants for any further comments, additions or corrections that they felt were necessary. Five of the six participants returned their transcripts and all five were virtually unchanged. One participant had added some further notes, thoughts that she felt she had not fully expressed during the interview, but these just expanded on what she had already said rather than providing new material. The transcripts were analysed using thematic qualitative analysis (Huberman and Miles, 1988).

There were several ethical issues to be considered in approaching this group of recovered eating disorder sufferers. It was anticipated that dor- 
mant emotional feelings might be aroused even by the initial information pack and respondents were informed within the pack that they could contact the researcher for any further information to allay their fears or withdraw at this or at any later stage. The interviews were carried out by the researcher, a qualified counsellor with experience and specialist training within the field of eating disorders. In the event that during the interview the participant expressed a wish or demonstrated a need for further support or counselling, they were referred back to the agency that had agreed at the outset of the project to supply such further counselling or support. To preserve confidentiality and to prevent the disclosure of any personal data beyond the researcher, basic information forms were kept separate from interview data in a locked cabinet. Interview transcripts were coded, rather than named, and likewise kept secure in a separate place. After transcription the interview tapes were destroyed. All this information was included in the ethics application to the relevant committee at the University of Herefordshire which was approved.

\section{Results}

The length of time taken to recognize, even to themselves, that there was a problem immediately became apparent in analysing the results from the six participants. However their stories showed a huge ambivalence with a tension between the wish to have help and be noticed and a desire to keep the problem hidden. The participants spent long periods of time, in one case 10 years, enjoying their ability to maintain habits that kept them thin. These habits were sometimes anorexic, restricting food intake to the point of starvation, but more often bulimic. As one participant said, 'I'm not very good at not eating so making myself sick was brilliant', for another purging came in a different form: 'I wasn't able to make myself sick so I went out and bought some laxatives and took 10 and that worked really well'. All the participants spent years with their secret. Yet the theme running through the research was an overriding desire from the participants 'to have someone notice' and this comment referred to both immediate family and the wider community of friends and their general practitioner (GP). Yet they seemed unable to ask for help from siblings, relatives, friends or teach- ers. All the participants agreed that any help that was eventually offered fell far short of that which they felt they needed.

Most of the participants' mothers played both a passive and active role in their daughters' illnesses and also both a negative and positive role. At a very young age participants were made aware of their mothers' weight consciousness and were taught how to go on a diet and count calories:

... When I was about seven my mum went on a diet and she would write down calories and what she had had that day and she would explain to me about calories and how you could burn up calories with exercise and I became very conscious of that ...

Mothers also made passing comments about their young daughters' weight and shape without realising the huge impact their own behaviour and comments were making. As one participant said 'How do you stop what your mum says and the thoughts she puts in your head'. Feminist literature (Eichenbaum and Orbach, 1983) has provided insight into how eating disorders may be transgenerationally transmitted by mothers not recognizing their daughters' needs and preparing them for a restricted life catering to the needs of others. Yet it was also the participants' mothers who were the initiators of any open acknowledgement that their daughters might have a problem.

\section{Experiences of health professionals}

Participants who were taken to their GP by their mothers all seem to have had the same experience. The mothers were often able to articulate the fact that their daughters were not eating and were too thin but the responses from the GP were always negative, ranging from 'Well I think she is burning the candle at both ends. Go away and eat' to 'It is probably just a teenage thing'. Often the GP just handed out a diet sheet. Participants who made frequent visits to their GP on their own for other reasons, such as depression, feeling down, illness or even for the contraceptive pill, stated that they were very thin at the time of the visits but no medical personnel identified the underlying reasons for the visits:

... The doctors didn't pick up on it. I used to go to the doctor to get the 'pill' and I suffered from tonsillitis a lot, and I remember 
thinking, how come they haven't picked up on the weight I've lost, it always used to amaze me ...

The doctors responded to the ostensible reasons for the visits with statements such as 'It is just your hormones. You will grow out of it'. One participant summed it up by saying:

... There was a lack of recognition by my doctor in the early stages and then he panicked because it might have gone too far. You are either bad enough to be put in hospital or left to your own devices ...

Some of the participants had been referred to a psychiatrist. There seems to have been confusion in understanding the role of the psychiatrist and therefore expectations were rarely met. Participants suggested that the psychiatrists they had seen had not been compassionate or caring and indeed had been easy to lie to. Even when participants were diagnosed with an eating disorder they were told that they would have to wait months for any further help either as an inpatient or outpatient at a specialized eating disorder unit. There was no understanding by the participants that this may have been due to lack of resources within the NHS, because this was never fully explained.

Some participants were referred to a practice nurse or counsellor or to a community psychiatric nurse (CPN). These were seen as 'lovely ladies' who really wanted to help but had no real comprehension of how to deal with the illness. One participant said, 'My CPN was lovely but I think I knew more about eating disorders than she did'. Another who saw a counsellor attached to her GP's practice said 'She gave me a little bit more of a positive attitude but I don't think she took the case seriously as she kept on cancelling'. Practice nurses who again have no specialized training made comments such as 'You're not fat' but as one participant said 'It doesn't matter what someone tells you because it's not what you think'. The participants all seemed to concur with the concepts that suggest that working with eating disordered patients without specialized training is fraught at any level. As one participant said:

... You can say a hundred things that are right and they will make you feel a little bit good but you can say one thing that is wrong and it will make you feel very bad ...
Only one participant had had in-patient treatment at a private clinic for adolescents with eating disorders. Her comments were:

... They did make me eat, they stopped me from dying. As for solving the problem, considering that 18 months later I was back where I started almost, that wasn't tackled at all. There was no focus on the personality or the anxiety that I feel is the problem ...

Three participants had used Internet sites for differing purposes. Two participants used it as a means of gaining information and help but a third discovered the Pro-Ana sites. These are sites that encourage anorexia and bulimia and give help in hiding all the various devices used to maintain the illness. This participant said:

... I went on the Internet and was reading about all these people who were making themselves sick and they were eating what they wanted and losing weight ...

Until reading this she had not thought of doing this and acknowledges that at the time she thought the Internet a really helpful place. Only now could she recognize how destructive these sites were for her as an adolescent.

Another aspect of the media that was repeatedly articulated as being an incredibly destructive force was the number of available magazines displaying and applauding the body image of unnaturally thin female celebrities. They often contain exercise regimes and diets so that the adolescent girl reader can strive to achieve a similar shape. As one participant said 'That is what all the magazines are about so that is all girls see and it's all they know and I don't think they stand a chance'. Wolf (1991) describes that over the last decades, as women have broken through male dominated power structures, so they have also become more and more enslaved by concerns surrounding their physical image.

Altogether the six participants had a generally negative view of help that had been available to them prior to discovering the agency in Luton. They seem to suggest that unless you are in the 'danger zone' there is no help that is readily available and accessible at primary care level.

It is important to note that although all six participants had had such negative views of their GPs, three had been able to subsequently change GPs 
and had latterly found doctors who were sympathetic and understanding. One participant said that her GP (a woman) had self-disclosed that she had at one time been bulimic and this had created greater trust in the GP and the belief that the GP could better understand the problem.

\section{Experiences of the agency}

This theme of another person having experienced the illness, enabling greater understanding, created a belief of positive assistance being available to all six participants when they finally arrived at the agency. The young woman running the agency herself had suffered from an eating disorder for a period of 10 years and had published a book (Beeken with Greenstreet 1997) detailing her experiences and her belief in the way forward.

The six participants had all come to the agency with a history of negative experiences and described the agency and the young woman who ran it as their 'last hope'. They were all at an extremely low point both physically and mentally but, together with their hopes, they were also sceptical of that which might be on offer. It seemed as if even meeting this young woman was cathartic for them, as she seemed to speak a language they understood. There were many comments such as 'I know that she has been there and she understands' and 'She understood like no one has ever understood what I have been through'.

All participants mentioned the 'food plan' that had been devised by the agency, by which the participants are required to eat six small meals a day. The participants all reported weighing themselves at first, discovering they had not put on any weight, and gradually relaxing, enabling them to trust the food plan and its benefits. Gradually, some of their obsessive behaviour ceased and they could concentrate on the other aspects of their individual eating disorder.

All the participants had initially attended one or two individual counselling sessions at the agency where, 'she (the woman who ran the agency) made me look at things in a different way. . . she let me talk until I had talked some sense into myself' and five of these participants had then been encouraged to attend a 10-week food behaviour programme group. Many of the participants suggested that they were initially suspicious of the other members of the group, believing themselves to be in compe- tition with people who were even thinner than themselves. As one participant said:

... Talking about our experiences was good ... there was this one girl who was so thin and I really, really wanted to look like her but when I heard about how ill she was and how much she couldn't do, it reminded me of how ill I had been and how it is not worth being that thin ...

This very much represented all the participants' experience of the group, which could also be summed up in the words of another participant who said:

... I was surprised at how unfocused it was on food ... we worked on self-esteem, problem solving and not trying to build ourselves unreasonable targets. It was also acknowledged that it was not about weight but an illness and an addiction and gave me space to step back and look at my life as a whole, not just my weight ...

\section{Participants' reflections on other possible sources of help}

All six participants acknowledged that even though their eating disorder had not always manifested itself as such until postadolescence, at a very early age they had all developed a sometimes obsessive interest in their body image and weight, which was inevitably linked to their self-esteem. Participants remembered events such as:

... When I was seven we went over to friends for dinner and when I had an extra helping the elder daughter, who I looked up to, said you don't want to eat any more of that or you'll get fat. I remember that this horrendous feeling came over me that I mustn't get fat because that would be really awful even though I was a skinny seven year old ...

and

... When I was nine I thought I was really fat and cried when I had to go swimming with school. People made comments about my chunky legs, tree trunk legs, and even now they are my biggest thing ...

They therefore all felt that eating disorder education at school at age 12 to 13 would be of prime 
importance and perhaps groups similar to that experienced at the agency would be useful. Comments ranged from 'School is a good place because that is where you catch most people' and 'There should be more teaching about it at school. There is so much about drug awareness and smoking and drinking but very little about eating disorders'

All the participants perceived the young woman who ran the agency as a positive role model, considering that someone who had survived the dire outcome of the illness as she had would be the ideal person to come in to school and talk about her experiences. Other features of education they would have liked would cover body image, selfesteem and how the media portrays women:

... You need to teach children to be individual ... to have confidence in themselves ... because now, I dress how I want to dress ... . I wear my hair how I want to wear my hair ... I won't conform. I still have fat days, I'm a normal girl, but I try to ignore them. I have friends that are a size six and they still have fat days ...

and

... Try to create a healthy attitude towards weight. How a woman should feel and not just how she should look ... why should she look like anything, she should just look how she wants to look, not how she is expected to ...

One participant had been able to acknowledge, through her counselling at the agency, that she was gay and felt that the uncertainties that had given rise to her anorexia could have been addressed by better education and pastoral care surrounding aspects of sexuality within the school environment. Participants wanted school counsellors who would be easily accessible but also within a confidential setting. They all talked about professionals needing to be more educated but conceded that, although it would be preferable that all counsellors should have experienced the illness themselves, what was important was that a health professional did not present an external picture of knowledge which was not supported by a real knowledge and sense of understanding. A participant seemed to sum up what was required by saying:

... A group that focuses off the food and off the weight is what is needed because cer- tainly, when you are an adolescent, that is all you talk about ...

Participants felt that they would like information that was much more easily and anonymously attainable at places such as GP's surgeries and libraries. As one participant said 'I've been to so many doctors' surgeries just to see if they have leaflets and none of them have leaflets about eating disorders, none of them at all'.

As has been noted previously, some participants felt that their mothers had been instrumental in initiating thoughts surrounding their weight and body image and there was a general wish for more maternal education in the areas of self-esteem, body image and also in eating disorders themselves. As one participant said 'A lot of my problems stem back from my mother and it would have benefited her to have had help'.

\section{Discussion}

Although 34 letters were initially despatched there was a surprisingly low response rate of only $18 \%$. Obviously this low response rate, together with the small sample rate, means that the results can only be suggestive. There are a number of reasons that might account for this. Eating disorders become shameful to acknowledge and this may have affected willingness to participate in research. Additionally, it became obvious during the interviews that the participants did not want to maintain friendships made within the group, saying that leaving the illness behind meant leaving anything that might drag them back into the thought processes associated with the illness. Perhaps the researcher's request for help was seen as part of that phenomenon. Alternatively, if some of the clients that were contacted had by that time suffered a relapse, then that might have made it difficult for them to respond, admitting to a setback.

The participants were all clients of the agency and had all arrived there feeling it was their last resort. They had all gained enormously from their experiences with the agency and the young woman who ran it. This seems to have coloured their views of what they thought would have been helpful for them earlier in their illness and what should be put in place now. This is a further limitation on the generalizations of the conclusion. 
The concrete suggestion of the participants for school education may be somewhat naive and has been explored previously with varying degrees of success being reported. Research into the prevention of eating disorders (O'Dea 2000) suggests that providing direct information about eating disorders and problem eating, no matter how well meaning, may inadvertently serve to introduce young people to the beliefs, attitudes and behaviours that precede eating problems. Gresko and Rosenvinge (1998) conclude that we do not prevent eating disorders just by talking about them. Information is insufficient in terms of primary prevention. Rather, a prevention strategy means returning to the children their self-confidence and belief in their own intrinsic value to counterbalance the adverse sociocultural factors. Piran (1999) seems to have had some success with her work where she uses a feminist approach to the prevention of body weight and shape preoccupation. She promotes a feminist programme that acknowledges the importance of voice, power, lived experience and relationships. Her programme works towards creating a safe and equitable school system in which the voices of diverse young women are heard and women's bodies are no longer a site of societal oppression. All three of these programmes have had some long-term success and concur with ideas towards which this pilot study is pointing in terms of primary prevention education, preferably in a school setting.

\section{Implications for primary care workers}

Along with suggestions for more education at school, the participants all wanted more specific education for health professionals. This may need to include information and training to prepare professionals to respond more empathically to patients with eating disorders. This mirrors results that were published 10 years ago as part of the study made by the Eating Disorders Association in 1992 (Newton et al., 1993). It is unfortunate to have to record that since that time there has been little change and help still falls short of that which the eating disordered patient requires at primary care level.

\section{Indications of what is required at primary care level}

- Support and Information via GPs' surgeries.
- An informed and empathic response from health professionals at initial contact.

- Easy access to appropriately trained counsellors.

Finally, for future research, it would be helpful to create a larger study, which would use as its base a more diverse group of participants from a wider geographical area and a wider sphere of experience. As this limited research project concurs with previous research, it seems to suggest that further research might culminate in the same conclusions. This may support bids for funding for a primary intervention project in a secondary school. It may also encourage Primary Care Trusts to recognize the shortfall in service provision at present and that the means by which that may be corrected are relatively simple and low cost.

\section{Acknowledgements}

The authors would like to thank Claire Beeken, Ann Etkind, Dr Helen Payne, Keith Price, Abigail Rose and the research participants.

\section{References}

American Psychiatric Association. 1994: Diagnostic and statistical manual of mental disorders (4th edn). Washington, DC: American Psychiatric Association.

Beeken, C. and Greenstreet, R. 2000: My body, my enemy. London: Thorsons.

Consumers' Association. 1998: Eating disorders. Health Which? 24-27.

Department of Health. 1996: National health service psychotherapy services in England, summary of strategic policy. London: Department of Health.

Department of Health. 1999: National service framework for mental health. Modern standards and service models. London: Department of Health.

East and North Herfordshire Health Authority, West Hertfordshire Health Authority, Herfordshire Social Services and Herfordshire Education Authority. 2000a: Herfordshire child, adolescent and family mental health services strategy. Herfordshire: East and North Herfordshire Health Authority, West Hertfordshire Health Authority, Herfordshire Social Services and Herfordshire Education Authority.

East and North Herfordshire Health, West Herfordshire Health Authority and Herfordshire County Council. 2000b: Mental health national service framework, Herfordshire local implementation plan 2000-2001. Herfordshire. East and North

Primary Health Care Research and Development 2004; 5: 153-161 
Herfordshire Health, West Hertfordshire Health Authority and Herfordshire County Council.

Eating Disorders Special Interest Group of the Royal College of Psychiatrists. 2000: Eating disorders in the UK: policies for service development and training. London: Royal College of Psychiatrists.

Eichenbaum, L. and Orbach, S. 1983: Understanding women. London: Penguin.

Goldbloom, D.S. and Kennedy, S.H. 1995: Medical complications of anorexia nervosa. In Brownell, K.D. and Fairburn, C.G., editors, Eating disorders and obesity. New York: Guilford Press, 266-70.

Gowers, S.G., Weetman, J., Shore, A., Hossain, F. and Elvins, R. 2000: Impact of hospitalisation on the outcome of adolescent anorexia nervosa. British Journal of Psychiatry 176, 138-41.

Gresko, R.B. and Rosenvinge, J.H. 1998: The Norwegian schoolbased prevention model: development and evaluation. In Vandereycken, W. and Noordenbos, G., editors, The prevention of eating disorders. London: The Athlone Press, 75-98.

Hill, K. and Pomeroy, C. 2001: Assessment of body image disturbance in children and adolescents. In Thompson, J.K. and Smolak, L., editors, Body image, eating disorders, and obesity in youth. Washington, DC: American Psychological Association, 171-91.

Hsu, L.K.G. 1995: Outcome of bulimia nervosa. In Brownell, K.D. and Fairburn, C.G., editors, Eating disorders and obesity. New York: Guilford Press, 238-44.

Huberman, A.M. and Miles, M.B. 1988: Data management and analysis methods. In Denzin, N.K. and Lincoln, Y.S., editors, The landscape of qualitative research: theories and issues. London: Sage, 179-207.
Mitchell, J.E. 1995: Medical complications of bulimia nervosa. In Brownell, K.D. and Fairburn, C.G., editors, Eating disorders and obesity. New York: Guilford Press, 271-75.

Newton, T. Robinson, P. and Hartley, P. 1993: Treatment for eating disorders in the United Kingdom. Part II. Experiences of treatment: a survey of members of the Eating Disorders Association. Eating Disorders Review 1, 10-21.

O'Dea, J. 2000: School-based interventions to prevent eating problems: first do no harm. Eating Disorders: The Journal of Treatment and Prevention 8, 123-30.

Piran, N., Levine, M.P. and Steiner A.C. editors. 1999: Preventing eating disorders. A handbook of interventions and special challenges. Philadelphia, PA: Brunner Mazel.

Robinson, P. 1993: Treatment for eating disorders in the United Kingdom. Part I. A survey of specialist services. Eating Disorders Review 1, 4-9.

Shisslak, C.M., Crago, M. and Estes, L.S. 1995: The spectrum of eating disturbances. International Journal of Eating Disorders 18, 209-19.

Steinhausen, H.-C. 1995: The course and outcome of anorexia nervosa. In Brownell, K.D. and Fairburn, C.G., editors, Eating disorders and obesity. New York: The Guilford Press, 234-37.

Stice, E. 2001: Risk factors for eating pathology: recent advances and future directions. In Striegel-Moore, R.H. and Smolak, L., editors, Eating disorders: innovative directions in research and practice. Washington, DC: American Psychological Association, 51-73.

Thompson, J.K. and Smolak, L., editors, 2001: Body image, eating disorders and obesity in youth. Washington, DC: American Psychological Association.

Wolf, N. 1991: The beauty myth. London: Vintage. 